\title{
Inventory-based estimation of aboveground net primary production in Japan's forests from 1980 to 2005
}

\author{
Y. Wang ${ }^{1, *}$, J. Y. Fang ${ }^{1}$, T. Kato ${ }^{2}$, Z. D. Guo ${ }^{1}$, B. Zhu ${ }^{1, * *}$, W. H. Mo ${ }^{3}$, and Y. H. Tang ${ }^{4}$ \\ ${ }^{1}$ Department of Ecology, College of Urban and Environmental Sciences, and Key Laboratory for Earth Surface Processes of \\ the Ministry of Education, Peking University, Beijing 100871, China \\ ${ }^{2}$ Research Institute for Global Change, Japan Agency for Marine-Earth Science and Technology, Yokohama, Kanagawa \\ 236-0001, Japan \\ ${ }^{3}$ National Institute for Agro-Environmental Sciences, Tsukuba, Ibaraki 305-8604, Japan \\ ${ }^{4}$ National Institute for Environmental Studies, Onogawa 16-2, Tsukuba Ibaraki 305-8506, Japan \\ *now at: Department of Biological Sciences, Graduate School of Science, The University of Tokyo, Tokyo 113-0033, Japan \\ ** now at: Department of Environmental Studies, University of California, Santa Cruz, California 95064, USA
}

Received: 25 November 2010 - Published in Biogeosciences Discuss.: 17 February 2011

Revised: 25 June 2011 - Accepted: 5 July 2011 - Published: 4 August 2011

\begin{abstract}
Recent studies based on remote sensing and carbon process models have revealed that terrestrial net primary production (NPP) in the middle and high latitudes of the Northern Hemisphere has increased significantly; this is crucial for explaining the increased terrestrial carbon sink in the past several decades. Regional NPP estimation based on significant field data, however, has been rare. In this study, we estimated the long-term changes in aboveground NPP (ANPP) for Japan's forests from 1980 to 2005 using forest inventory data, direct field measurements, and an allometric method. The overall ANPP for all forest types averaged $10.5 \mathrm{Mg} \mathrm{ha}^{-1} \mathrm{yr}^{-1}$, with a range of 9.6 to $11.5 \mathrm{Mg} \mathrm{ha}^{-1} \mathrm{yr}^{-1}$, and ANPP for the whole country totaled $249.1 \mathrm{Tg} \mathrm{yr}^{-1}$ (range: 230.0 to $271.4 \mathrm{Tg} \mathrm{yr}^{-1}$ ) during the study period. Over the 25 years, the net effect of increased ANPP in needle-leaf forests and decreased ANPP in broadleaf forests has led to an increase of $1.9 \mathrm{Mg} \mathrm{ha}^{-1} \mathrm{yr}^{-1}$ (i.e., $0.79 \% \mathrm{yr}^{-1}$ ). This increase may be mainly due to the establishment of plantations and the rapid early growth of these planted forests.
\end{abstract}

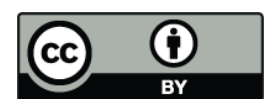

Correspondence to: J. Y. Fang (jyfang@urban.pku.edu.cn)

\section{Introduction}

Net primary production (NPP) is defined as the rate of accumulation of organic matter by vegetation and equals the difference between carbon assimilated by plants through photosynthesis and the carbon consumed by plant autotrophic respiration (Chapin et al., 2002). NPP therefore represents the efficiency of $\mathrm{CO}_{2}$ fixation by plants, determines the amount of materials and energy available for heterotrophic organisms, and represents the activity of vegetation in the global carbon cycle (Jenkins et al., 2001). Recent results from satellite remote sensing and carbon process models have suggested that NPP has increased in the middle and high northern latitudes since the 1980s (Myneni et al., 1997, 2001; Hicke et al., 2002; Fang et al., 2003; Nemani et al., 2003; Piao et al., 2005) and that this increase was crucial for explaining the increased terrestrial carbon sink. However, regional NPP estimates based on significant field data are rare, especially over long time scales (Turner et al., 1999; Fang et al., 1996; Brown and Schroeder, 1999; Kurz and Apps, 1999; Jenkins et al., 2001; Brown, 2002).

Biomass-based NPP estimation has been considered an effective method to assess NPP variations on a national scale (Whittaker and Marks, 1975; Fang et al., 1996; Jenkins et al., 2001; Brown, 2002). Whittaker and Marks (1975) detected a linear relationship between biomass and NPP for the first time, and Fang et al. (1996) developed this method by establishing several allometric biomass-NPP relationships for major forest types and using the allometries to estimate NPP for China's forests. Jenkins et al. (2001), using plot-level forest inventory data, also reported a linear relationship between

Published by Copernicus Publications on behalf of the European Geosciences Union. 
biomass and NPP for the mid-Atlantic region of the United States. A positive biomass-NPP relationship is useful for estimating NPP because biomass can be easily obtained from forest inventory data, which have become increasingly complete and available for many countries and regions in recent decades.

Japan has a typical marine climate with abundant rainfall, and two-thirds of its land area is covered with forest (Kira, 1991). Since the International Biological Program (IBP, 1965 to 1974), biomass and NPP have been measured extensively for the main forest types in Japan (Fang et al., 2005). In addition, a systematic forest inventory has been conducted in Japan at about $5 \mathrm{yr}$ intervals since 1947, and the surveys have intensified since the 1980s (Fang et al., 2005). These direct field measurements and systematic forest inventories make it possible to investigate the historical changes in NPP for Japan's forests.

In order to estimate changes in biomass in Japan's forests over time, we reviewed the research literature on Japan's forests and compiled a database for Japan's forest biomass (Fang et al., 2005). Based on this database and forest inventory data, we investigated changes in the biomass of Japan's forests from 1947 to 1995 in the previous study (Fang et al., 2005). In this study, we further complemented the database with NPP datasets, developed allometric relationships between aboveground biomass (AB) and aboveground NPP (ANPP) for Japan's major forest types, and investigated the changes in ANPP in Japan's forests from 1980 to 2005.

\section{Data and methods}

We estimated the ANPP of Japan's forests based on biomassNPP relationships and data from forest inventories. Therefore, we used two datasets in this study: direct field measurements, including both biomass and NPP, and data from forest inventories.

\subsection{Field measurement data}

Since the IBP, studies of biomass and NPP have been conducted for Japan's major forest types. Cannell (1982) compiled a global database of forest biomass and NPP, including some data from Japan. Fang et al. (2005) developed a database of Japan's forest biomass that included 945 sets of data. We started with this database, then collected additional NPP data for Japan's forests from all the available literature to establish a new database. This new database contains the forest type, stand age, stand density, total basal area, stand volume, stem biomass, $\mathrm{AB}$, belowground biomass, biomass of forest-floor vegetation, and 572 sets of NPP data. The NPP data generally included stem NPP $\left(\mathrm{NPP}_{\mathrm{S}}\right)$, branch NPP $\left(\mathrm{NPP}_{\mathrm{B}}\right)$, and leaf NPP $\left(\mathrm{NPP}_{\mathrm{L}}\right)$, and some of them also include root NPP (belowground NPP, BNPP) or total NPP $($ TNPP $=$ ANPP + BNPP). Unfortunately, there
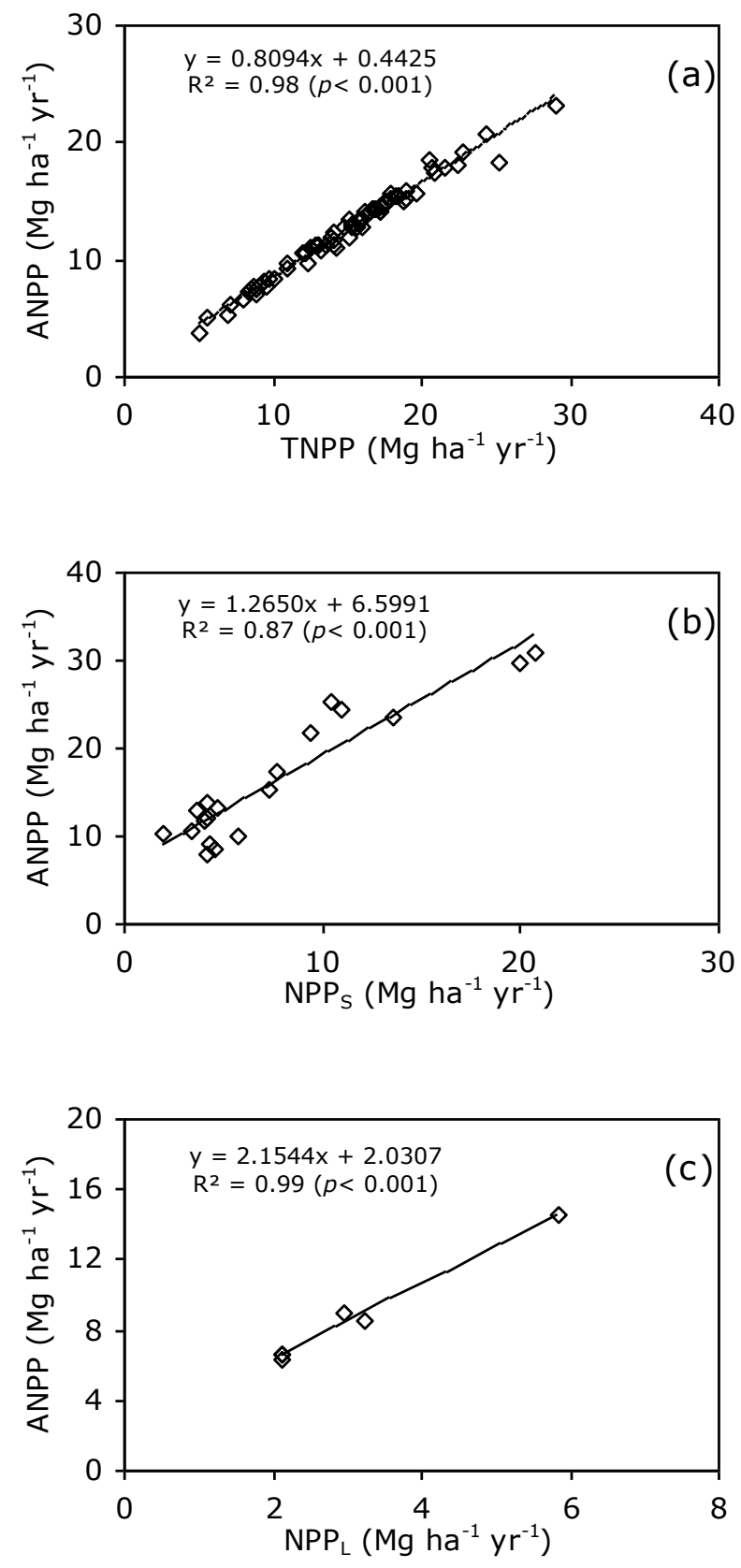

Fig. 1. Examples of the relationships between the components of net primary production (NPP) and aboveground net primary production (ANPP). (a) The relationship between total net primary production (TNPP) and ANPP for C. japonica forests. (b) The relationship between stem net primary production $\left(\mathrm{NPP}_{S}\right)$ and ANPP for evergreen broadleaf forests. (c) The relationship between leaf net primary production $\left(\mathrm{NPP}_{\mathrm{L}}\right)$ and ANPP for needle-leaf and broadleaf mixed forests. The relationships between these NPP components and ANPP for other forest types are shown in Table 1. 

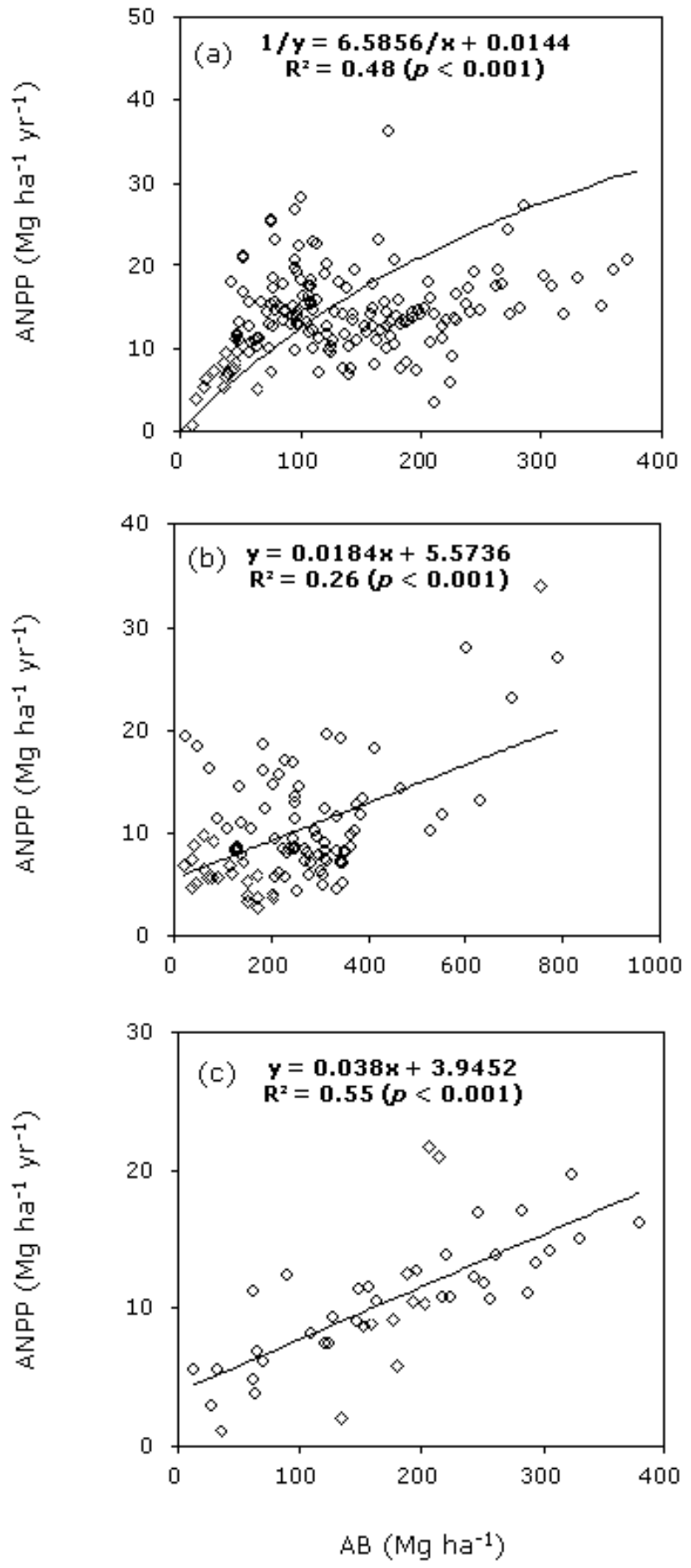

Fig. 2. Examples of the relationships between aboveground biomass $\left(\mathrm{AB}, \mathrm{Mg} \mathrm{ha}^{-1}\right)$ and aboveground net primary production (ANPP, $\mathrm{Mg} \mathrm{ha}^{-1} \mathrm{yr}^{-1}$ ) for three of the main forest types in Japan. (a) C. japonica forests, (b) other deciduous broadleaf forests, and (c) Abies and Picea forests. Table 2 presents details of the regression analysis for all forest types. was insufficient longer-term BNPP data for us to reconstruct BNPP changes during the study period. We defined ANPP as the sum of $\mathrm{NPP}_{\mathrm{S}}, \mathrm{NPP}_{\mathrm{B}}$, and $\mathrm{NPP}_{\mathrm{L}}$. All the NPP data were estimated by means of destructive sampling and were defined as the difference in biomass and litterfall between two survey years divided by the number of years between measurements, thereby providing the net biomass and litterfall change per year. In this study, we defined "biomass" as the standing crop $\left(\mathrm{Mg} \mathrm{ha}^{-1}\right)$. In this study, biomass and ANPP are all dry-matter based.

\subsection{Calculation of ANPP from other NPP components}

Since some of the original sets did not provide ANPP data and instead presented only data on $\mathrm{NPP}_{\mathrm{S}}, \mathrm{NPP}_{\mathrm{L}}$, or TNPP, we estimated the ANPP for each dataset using allometric relationships between the various NPP components and ANPP. We developed three allometric relationships to perform this analysis: (1) the TNPP-ANPP relationship, (2) the $\mathrm{NPP}_{\mathrm{S}}$ ANPP relationship, and (3) the $N_{P} P_{L}-A N P P$ relationship. Figure 1 shows typical examples of these relationships, and Table 1 lists the regression results for the sets of data that required this allometric approach. As shown in Table 1 and Fig. 1, strong and significant linear correlations were found between the NPP components (such as $\mathrm{NPP}_{\mathrm{S}}, \mathrm{NPP}_{\mathrm{L}}$ ) or TNPP and ANPP, suggesting that our approach is an acceptable way to obtain ANPP data from studies that presented only NPP components.

\subsection{Relationship between biomass and ANPP}

Biomass is generally considered to represent the accumulation of plant organic matter during a plant's life cycle. During a forest's growth stages, ANPP tends to increase with increasing AB (Whittaker and Marks, 1975; Fang et al., 1996; Jenkins et al., 2001; Brown, 2002). Therefore, previous studies established the biomass-NPP relationship based on field measurements and used biomass to estimate the changes in NPP (Whittaker and Marks, 1975; Fang et al., 1996; Jenkins et al., 2001). In the present study, we used our new database to establish a series of relationships between $\mathrm{AB}$ and ANPP for Japan's main forest types. To document the contribution of various forest types to Japan's total ANPP, we classified the country's forests into 10 major types: Cryptomeria japonica forests, Chamaecyparis obtusa forests, $P i$ nus forests, Larix leptolepis forests, Abies and Picea forests, other needle-leaf forests, Quercus forests, other deciduous broadleaf forests, evergreen broadleaf forests, and needleleaf and broadleaf mixed forests (For the details of the dominant species in each of the forest types, see Table S1). Figure 2 presents typical examples of the relationships between $\mathrm{AB}$ and ANPP, and Table 2 presents the regression results for all of these forest types. Table 2 and Fig. 2 both show strong and significant $(p<0.05)$ relationships between $\mathrm{AB}$ and ANPP for most forest types, with the exception of evergreen 
Table 1. Regression parameters for the relationships between aboveground net primary production (ANPP) and total NPP (TNPP), stem $\mathrm{NPP}\left(\mathrm{NPP}_{\mathrm{S}}\right)$, and leaf NPP $\left(\mathrm{NPP}_{\mathrm{L}}\right)$ for Japan's major forest types, where $a$ and $b$ are the regression constants for each forest type. The units of all NPP components are $\mathrm{Mg} \mathrm{ha}^{-1} \mathrm{yr}^{-1}$. All regressions were statistically significant $(p<0.001)$.

\begin{tabular}{|c|c|c|c|c|c|c|c|c|c|c|c|c|}
\hline \multirow{2}{*}{ Forest type } & \multicolumn{4}{|c|}{$\mathrm{ANPP}=a \mathrm{TNPP}+b$} & \multicolumn{4}{|c|}{$\mathrm{ANPP}=a \mathrm{NPP}_{\mathrm{S}}+b$} & \multicolumn{4}{|c|}{$\mathrm{ANPP}=a \mathrm{NPP}_{\mathrm{L}}+b$} \\
\hline & $a$ & $b$ & $R^{2}$ & $n$ & $a$ & $b$ & $R^{2}$ & $n$ & $a$ & $b$ & $R^{2}$ & $n$ \\
\hline Cryptomeria japonica forests & 0.8094 & 0.4425 & 0.98 & 74 & 1.2927 & 3.7627 & 0.91 & 107 & & & & \\
\hline Chamaecyparis obtusa forests & 0.8800 & -1.0011 & 0.98 & 12 & 1.2635 & 3.6640 & 0.86 & 48 & & & & \\
\hline Other deciduous broadleaf forests & 0.8703 & 0.2064 & 0.98 & 27 & 1.2072 & 3.3053 & 0.87 & 10 & & & & \\
\hline Other needle-leaf forests & & & & & 1.9424 & 0.7924 & 0.88 & 12 & & & & \\
\hline Evergreen broadleaf forests & & & & & 1.2650 & 6.5991 & 0.87 & 19 & & & & \\
\hline Needle-leaf and broadleaf mixed forests & & & & & & & & & 2.1544 & 2.0307 & 0.99 & 6 \\
\hline
\end{tabular}

Table 2. Relationships between aboveground biomass (AB, $x$ ) and aboveground net primary production (ANPP, $y$ ) for the major forest types in Japan. SD = standard deviation.

\begin{tabular}{|c|c|c|c|c|c|c|c|c|c|c|}
\hline \multirow[t]{2}{*}{ Forest type } & \multicolumn{3}{|c|}{$\mathrm{AB}\left(\mathrm{Mgha}^{-1}\right)$} & \multicolumn{3}{|c|}{$\operatorname{ANPP}\left(\mathrm{Mg} \mathrm{ha}^{-1} \mathrm{yr}^{-1}\right)$} & \multicolumn{4}{|c|}{ AB-ANPP relationship } \\
\hline & Range & Mean & $\mathrm{SD}$ & Range & Mean & SD & Equation & $n$ & $R^{2}$ & $p$ \\
\hline Cryptomeria japonica forests & 10.5 to 371.0 & 136.8 & 75.9 & 0.7 to 36.3 & 14.3 & 5.2 & $1 / y=6.5856 / x+0.0144$ & 172 & 0.48 & $<0.001$ \\
\hline Chamaecyparis obtusa forests & 25.3 to 308.2 & 161.3 & 69.0 & 4.9 to 20.6 & 12.4 & 3.6 & $y=0.0152 x+9.9770$ & 85 & 0.08 & 0.007 \\
\hline Pinus forests & 24.7 to 222.1 & 96.5 & 51.4 & 5.6 to 20.3 & 11.8 & 3.8 & $1 / y=2.5151 / x+0.0582$ & 26 & 0.56 & $<0.001$ \\
\hline Larix leptolepis forests & 13.3 to 210.3 & 88.6 & 60.0 & 5.6 to 17.1 & 12.2 & 3.2 & $y=0.0416 x+8.5101$ & 26 & 0.61 & $<0.001$ \\
\hline Abies and Picea forests & 12.6 to 378.7 & 176.2 & 91.1 & 1.2 to 21.7 & 10.7 & 4.7 & $y=0.038 x+3.9452$ & 44 & 0.55 & $<0.001$ \\
\hline Quercus forests & 27.4 to 265.0 & 117.0 & 69.5 & 4.7 to 23.6 & 11.8 & 4.9 & $y=0.0489 x+6.1131$ & 26 & 0.48 & $<0.001$ \\
\hline Other deciduous broadleaf forests & 18.4 to 787.4 & 250.7 & 151.4 & 2.8 to 34.0 & 10.2 & 5.5 & $y=0.0184 x+5.5736$ & 101 & 0.26 & $<0.001$ \\
\hline Evergreen broadleaf forests & 19.5 to 377.6 & 99.8 & 87.9 & 7.8 to 30.8 & 15.4 & 5.4 & Mean $=15.4$ & 67 & & \\
\hline Needle-leaf and broadleaf mixed forests & 86.1 to 559.7 & 308.5 & 203.4 & 6.4 to 16.2 & 9.4 & 3.6 & Mean $=9.4$ & 9 & & \\
\hline
\end{tabular}

Table 3. Forest area, mean aboveground biomass (AB), mean aboveground net primary production (ANPP), and total ANPP for Japan's major forest types from 1980 to 2005. CRYJAP, C. japonica; CHAOBT, C. obtusa; Larix, L. leptolepis; ABI \& PIC, Abies and Picea; OtherN, Other needle-leaf forests; OtherB, Other deciduous broadleaf forests and Evergreen broadleaf forests.

\begin{tabular}{|c|c|c|c|c|c|c|c|c|c|c|c|c|}
\hline \multirow{2}{*}{ Item } & \multirow{2}{*}{ Period } & \multicolumn{7}{|c|}{ Needle-leaf forest } & \multicolumn{3}{|c|}{ Broadleaf forest } & \multirow{2}{*}{ Total } \\
\hline & & CRYJAP & СНАOBТ & Pinus & Larix & ABI \& PIC & OtherN & Subtotal & Quercus & OtherB & Subtotal & \\
\hline \multirow[t]{6}{*}{ Forest area $\left(10^{3} \mathrm{ha}\right)$} & 1980 & 4416 & 2177 & 3746 & 1129 & 3627 & 1104 & 16198 & 1140 & 6500 & 7640 & 23839 \\
\hline & 1985 & 4522 & 2392 & 2382 & 1100 & 5536 & 627 & 16560 & 1906 & 5315 & 7221 & 23781 \\
\hline & 1990 & 4590 & 2513 & 2592 & 1097 & 2638 & 814 & 14244 & 1890 & 7657 & 9546 & 23791 \\
\hline & 1995 & 4574 & 2600 & 2411 & 1084 & 2267 & 777 & 13713 & 2362 & 7609 & 9971 & 23685 \\
\hline & 2000 & 4545 & 2626 & 1998 & 1060 & 1820 & 1039 & 13087 & 3197 & 7222 & 10419 & 23506 \\
\hline & 2005 & 4528 & 2633 & 1903 & 1034 & 1617 & 767 & 12482 & 2946 & 8210 & 11156 & 23637 \\
\hline \multirow[t]{7}{*}{ Mean AB $\left(\mathrm{Mg} \mathrm{ha}^{-1}\right)$} & 1980 & 71.5 & 66.3 & 46.1 & 52.7 & 34.7 & 63.8 & 54.9 & 70.3 & 101.2 & 96.6 & 68.2 \\
\hline & 1985 & 84.8 & 74.2 & 70.7 & 68.8 & 30.1 & 102.7 & 62.7 & 53.5 & 134.6 & 113.2 & 77.9 \\
\hline & 1990 & 95.0 & 80.9 & 69.9 & 78.9 & 45.3 & 82.1 & 76.8 & 50.1 & 98.7 & 89.1 & 81.7 \\
\hline & 1995 & 108.2 & 91.7 & 78.4 & 89.4 & 51.5 & 82.9 & 87.5 & 22.9 & 108.2 & 88.0 & 87.7 \\
\hline & 2000 & 129.8 & 108.4 & 94.8 & 103.6 & 66.7 & 75.6 & 104.9 & 55.4 & 123.1 & 102.3 & 103.8 \\
\hline & 2005 & 144.9 & 121.2 & 106.6 & 112.0 & 74.2 & 113.3 & 120.2 & 53.3 & 116.7 & 100.0 & 110.7 \\
\hline & Mean* & 105.7 & 90.4 & 77.8 & 84.2 & 50.4 & 86.7 & 84.5 & 50.9 & 113.7 & 98.2 & 88.3 \\
\hline \multirow[t]{7}{*}{ Mean ANPP $\left(\mathrm{Mg} \mathrm{ha}^{-1} \mathrm{yr}^{-1}\right)$} & 1980 & 9.4 & 11.0 & 8.9 & 10.7 & 5.3 & 10.2 & 9.2 & 9.6 & 12.3 & 10.9 & 9.6 \\
\hline & 1985 & 10.9 & 11.1 & 10.7 & 11.4 & 5.1 & 10.2 & 9.9 & 8.7 & 12.3 & 10.5 & 10.0 \\
\hline & 1990 & 11.9 & 11.2 & 10.6 & 11.8 & 5.7 & 10.2 & 10.2 & 8.6 & 12.3 & 10.4 & 10.3 \\
\hline & 1995 & 13.3 & 11.4 & 1.1 & 12.2 & 5.9 & 10.2 & 10.7 & 7.2 & 12.3 & 9.7 & 10.4 \\
\hline & 2000 & 15.4 & 11.6 & 11.8 & 12.8 & 6.5 & 10.2 & 11.4 & 8.8 & 12.3 & 10.5 & 11.2 \\
\hline & 2005 & 16.7 & 11.8 & 12.2 & 13.2 & 6.8 & 10.2 & 11.8 & 8.7 & 12.3 & 10.5 & 11.5 \\
\hline & Mean* & 12.9 & 11.4 & 10.9 & 12.0 & 5.9 & 10.2 & 10.5 & 8.6 & 12.3 & 10.4 & 10.5 \\
\hline \multirow[t]{7}{*}{ Total ANPP $\left(\mathrm{Tg} \mathrm{yr}^{-1}\right)$} & 1980 & 41.4 & 23.9 & 33.2 & 12.1 & 19.1 & 11.2 & 149.6 & 10.9 & 79.6 & 83.3 & 230.0 \\
\hline & 1985 & 49.1 & 26.6 & 25.4 & 12.5 & 28.2 & 6.4 & 163.6 & 16.6 & 65.1 & 75.7 & 238.6 \\
\hline & 1990 & 54.8 & 28.2 & 27.5 & 12.9 & 15.0 & 8.3 & 145.8 & 16.2 & 93.8 & 99.3 & 244.5 \\
\hline & 1995 & 60.8 & 29.6 & 26.7 & 13.3 & 13.4 & 7.9 & 146.4 & 17.1 & 93.2 & 97.1 & 247.3 \\
\hline & 2000 & 69.8 & 30.5 & 23.6 & 13.6 & 11.8 & 10.6 & 148.9 & 28.2 & 88.5 & 109.8 & 262.5 \\
\hline & 2005 & 75.6 & 31.1 & 23.3 & 13.6 & 10.9 & 7.8 & 147.4 & 25.7 & 100.6 & 117.0 & 271.4 \\
\hline & Mean* & 58.6 & 28.3 & 26.6 & 13.0 & 16.4 & 8.7 & 150.3 & 19.1 & 86.8 & 97.0 & 249.1 \\
\hline
\end{tabular}

*Mean value of data from 1980 to 2005 . 
broadleaf forests, other needle-leaf forests, and needle-leaf and broadleaf mixed forests. For these three forest types, we used the mean value from the field data for our further analysis of ANPP.

\subsection{Forest inventory dataset}

Although Japan's Forest Resources Statistics are available from 1947 to 2005, only those since 1980 are complete and report both the forest area and total timber volume for each age class and each major forest type by prefecture (for the 47 prefectures in Japan). The data were compiled from 10000 statistically representative, adequately replicated, permanent sample plots across the country. The area of each plot is $1000 \mathrm{~m}^{2}$. In the present study, forest was defined as land with $20 \%$ or more crown cover of government-owned forests and more than $30 \%$ crown cover of community and privately owned forests. The data recorded included the forest group (planted and natural forests), owner, dominant tree species, age class, diameter at breast height, tree height, and stem volume. Biomass was estimated for each kind of forest from the timber volume. For a detailed description of forest inventories in Japan and the methods of biomass estimation, see Fang et al. (2005).

\section{Results}

Because of limitations in the earlier data from Japan's Forest Resources Statistics, we have focused on the changes in ANPP of Japan's forests only from 1980 to 2005. Table 3 summarizes the mean and total ANPP of Japan's forests for this period. The mean ANPP for all forest types combined averaged $10.5 \mathrm{Mg} \mathrm{ha}^{-1} \mathrm{yr}^{-1}$ during the $25 \mathrm{yr}$, and ranged from 9.6 to $11.5 \mathrm{Mg} \mathrm{ha}^{-1} \mathrm{yr}^{-1}$ (Table 3, Fig. 3). From 1980 to 2005, the mean ANPP increased markedly, by $1.9 \mathrm{Mg} \mathrm{ha}^{-1} \mathrm{yr}^{-1}$, with a mean annual increment of $0.076 \mathrm{Mg} \mathrm{ha}^{-1} \mathrm{yr}^{-1}(0.79 \%)$.

The mean ANPP of needle-leaf forests increased steadily throughout the study period (Fig. 3), with a mean annual increment of $0.10 \mathrm{Mg} \mathrm{ha}^{-1} \mathrm{yr}^{-1}(1.12 \%)$, giving a total increment of $2.6 \mathrm{Mg} \mathrm{ha}^{-1} \mathrm{yr}^{-1}$ (Table 3). In addition, the mean ANPP of most types of needle-leaf forest increased. The largest increase was for $C$. japonica forests, with a total increase of $7.3 \mathrm{Mg} \mathrm{ha}^{-1} \mathrm{yr}^{-1}$ over the $25 \mathrm{yr}$, followed by $\mathrm{Pi}$ nus forests, L. leptolepis forests, Abies and Picea forests, and $C$. obtusa forests, with increases of 3.3, 2.5, 1.5, and $0.8 \mathrm{Mg} \mathrm{ha}^{-1} \mathrm{yr}^{-1}$, respectively (Table 3 ). Because the ABANPP relationship for other needle-leaf forests was not significant (Table 2), we used the mean value of the field data in Table 3. Therefore, it is difficult to determine the changes in mean ANPP of this forest type during the study period.

In contrast, the mean ANPP of broadleaf forests showed a more complex pattern of changes. ANPP declined from 10.9 $\mathrm{Mg} \mathrm{ha}^{-1} \mathrm{yr}^{-1}$ in 1980 to $9.7 \mathrm{Mg} \mathrm{ha}^{-1} \mathrm{yr}^{-1}$ in 1995 , then

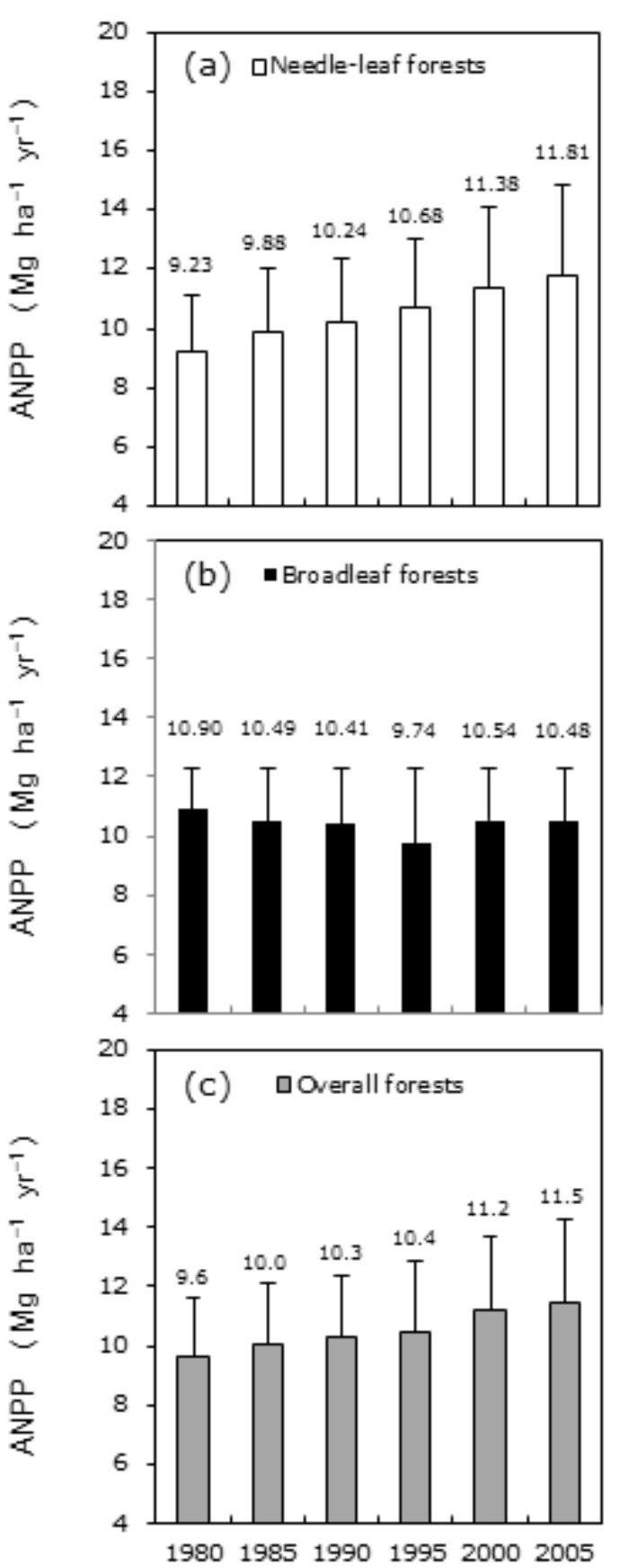

Fig. 3. Changes in mean aboveground net primary production (ANPP) of Japan's forests from 1980 to 2005: (a) needle-leaf forests; (b) broadleaf forests; (c) overall forests. The vertical lines extending from the top of boxes indicate standard errors of the means for different forests.

recovered to $10.5 \mathrm{Mg} \mathrm{ha}^{-1} \mathrm{yr}^{-1}$ in 2000 and remained at this level until 2005 (Table 3, Fig. 3). Overall, the mean ANPP of broadleaf forests decreased slightly (by $0.4 \mathrm{Mg} \mathrm{ha}^{-1} \mathrm{yr}^{-1}$ ) during the study period, with a mean annual decrement of $0.02 \mathrm{Mgha}^{-1} \mathrm{yr}^{-1}(0.15 \%)$. Because the data for other 
Table 4. Estimates of mean aboveground net primary production (ANPP) for Japan's forests and those of other northern countries or regions.

\begin{tabular}{|c|c|c|c|c|}
\hline Country or region & Period & Forest type & Mean ANPP $\left(\mathrm{Mg} \mathrm{ha}^{-1} \mathrm{yr}^{-1}\right)$ & Reference \\
\hline \multirow[t]{3}{*}{ Japan } & 1980 to 2005 & All & 10.5 & This study \\
\hline & & Broadleaf & 10.4 & This study \\
\hline & & Needle-leaf & 10.5 & This study \\
\hline China & 1984 to 1988 & All & $4.4^{*}$ & Fang et al. (1996) \\
\hline \multirow[t]{3}{*}{ United States (Mid-Atlantic region) } & & All & 8.5 & Jenkins et al. (2001) \\
\hline & & Broadleaf & 8.6 & Jenkins et al. (2001) \\
\hline & & Needle-leaf & 7.9 & Jenkins et al. (2001) \\
\hline \multirow[t]{2}{*}{ United States (eastern region) } & 1980 s to $1990 \mathrm{~s}$ & Broadleaf & 9.7 & Brown and Schroeder (1999) \\
\hline & & Needle-leaf & 8.7 & Brown and Schroeder (1999) \\
\hline Europe & 1995 to 2000 & All & $3.2(1.2$ to 8.0$)$ & Karjalainen et al. (2003) \\
\hline
\end{tabular}

* Including belowground NPP.

broadleaf forests in Table 3 represent the mean values for other deciduous broadleaf forests and evergreen broadleaf forests (Table 2), the changes in this forest type were not visible during the study period. Therefore, the majority of the change of mean ANPP of broadleaf forests resulted from changes in the mean ANPP of Quercus forests. Moreover, we noticed that the forests in two categories, "other needle-leaf forests" and "other broadleaf forests", did not show a clear trend in temporal variation both in area and other variables, compared with other forests. A possible error may exist in the inventory data due to land-surface classification differing in different periods. Further attention to the two forest types should be paid in the future because of their significant area, biomass, and productivity.

The total ANPP of Japan's forests (all types combined) averaged $249.1 \mathrm{Tg} \mathrm{yr}^{-1}$ during the study period and ranged from 230.0 to $271.4 \mathrm{Tg} \mathrm{yr}^{-1}$ (Table 3). Simultaneous with the increase of mean ANPP, the total ANPP of Japan's forests increased by $41.4 \mathrm{Tg} \mathrm{yr}^{-1}$ over the $25 \mathrm{yr}$, representing a mean annual increase of $1.66 \mathrm{Tg} \mathrm{yr}^{-1}(0.72 \%)$. However, in contrast with the trends for mean ANPP, the total ANPP of needle-leaf forests decreased by $2.2 \mathrm{Tg} \mathrm{yr}^{-1}$ from 1980 to 2005 (a mean annual rate of $0.06 \%$ ), whereas the total ANPP of broadleaf forests increased by $33.7 \mathrm{Tg} \mathrm{yr}^{-1}$ (a mean annual rate of $1.62 \%$ ) during the same period (Table 3). For specific forest types, the total ANPP increased most for the $C$. japonica forests, followed by other broadleaf forests, Quercus forests, C. obtusa forests, and L. leptolepis forests, which increased by $34.2,21.0,14.8,7.2$, and $1.5 \mathrm{Tg} \mathrm{yr}^{-1}$ over the $25 \mathrm{yr}$, respectively (Table 3 ). The reductions in total ANPP were greatest for Pinus forests, followed by Abies and Picea forests and by other needle-leaf forests, with decreases of $9.9,8.2$, and $3.4 \mathrm{Tg} \mathrm{yr}^{-1}$ over the $25 \mathrm{yr}$, respectively (Table 3 ).

\section{Discussion}

Our analysis revealed different patterns of change in the mean ANPP between needle-leaf and broadleaf forests (Fig. 3). This can be attributed to differences in the ratio of planted and natural forests for needle-leaf and broadleaf forests. In Japan, most of the planted forests are needleleaf forests. Moreover, due to the economic benefits and the pinewood nematode, the large area of deforestation of natural needle-leaf forests happened in recent decades, making the ratio of planted to natural forests increase from 1.5:1 to $4.1: 1$ (Table S2). Compared to natural forests, the wellmanaged plantations exhibited rapid early growth, resulting in a significant ANPP increment in needle-leaf forests from 1980 to 2005 . Conversely, more than $97 \%$ of the broadleaf forests were natural forests (Table S2). The area of old natural forests with high biomass density decreased rapidly, accompanied by a rapid increase in the area of young secondary forests with low biomass density, thereby decreasing the mean ANPP of broadleaf forests.

Interestingly, the directions of mean ANPP change for needle-leaf and broadleaf forests were the opposite of the directions for total ANPP. Because total ANPP was estimated by combining the mean ANPP with the total forest area, the forest area did play an important role in this difference. During the study period, the area of needle-leaf forests declined by $3.716 \times 106$ ha $(22.9 \%)$, whereas that of broadleaf forests increased by $3.516 \times 106$ ha $(46.0 \%)$ (Table 3$)$.

To compare mean forest ANPP in Japan with values from elsewhere, we summarized the mean forest ANPP for several key northern countries or regions in the Northern Hemisphere (Table 4). The overall mean ANPP of Japan's forests averaged $10.5 \mathrm{Mg} \mathrm{ha}^{-1} \mathrm{yr}^{-1}$ from 1980 to 2005 , and those of broadleaf forest and needle-leaf forest were 10.4 and $10.5 \mathrm{Mg} \mathrm{ha}^{-1} \mathrm{yr}^{-1}$, respectively. The mean ANPP of Japan's forests was more than two times the mean TNPP of China's forests (4.4 $\mathrm{Mg} \mathrm{ha}^{-1} \mathrm{yr}^{-1}$; Fang et al., 1996). Because TNPP equals the sum of ANPP and BNPP, the actual ANPP 
difference between Japan and China would be even greater. The mean ANPP of Japan's forests was also higher than that of forests in the eastern United States (ranging from 8.7 to $9.7 \mathrm{Mg} \mathrm{ha}^{-1} \mathrm{yr}^{-1}$; Brown and Schroeder, 1999) and the mid-Atlantic region of the United States $\left(8.5 \mathrm{Mg} \mathrm{ha}^{-1} \mathrm{yr}^{-1}\right.$; Jenkins et al., 2001). Europe had the lowest ANPP, with a mean of only $3.2 \mathrm{Mg} \mathrm{ha}^{-1} \mathrm{yr}^{-1}$ (ranging from 1.2 to 8.0 $\mathrm{Mg} \mathrm{ha}^{-1} \mathrm{yr}^{-1}$; Karjalainen et al., 2003). These results were consistent with those for the forest biomass carbon density of northern countries and regions reported by Fang et al. (2005). In their study, Japan's carbon sink was higher than that of other countries or regions, and this large carbon sink was mainly due to the rapid regrowth of plantations. Actually, high ANPP have been reported in some plantations in the southern United States (e.g., McNulty et al., 1996) and Europe (e.g., Xiao et al., 2003). It is note that, however, the NPP distinguished heavily not only depend on forest types, but also depend on site conditions, making it difficult to give reasonable judgment on plantation level all over the world. Therefore, in this study, we just roughly classified the forest to "Needle-leaf forest" and "Broadleaf forest" and pay attention on the studies reported on countries or regions level using the similar analysis method.

The large ANPP estimated in this study may also imply a large belowground net primary productivity (BNPP), since BNPP often vary proportionally with ANPP (Gower et al., 1997; Kajimoto et al., 1999; Xiao et al., 2003; Tateno et al., 2004; Hertel et al., 2009). However, these studies also indicate that the ratio of ANPP to BNPP can vary largely depending on physical environment, forest stand age and plant species composition etc. Therefore, the exact BNPP of the forests in Japan remains to be further explored in the future.

It is noteworthy that compared with other countries or regions, the mean ANPP of needle-leaf forests was comparable with that of broadleaf forests in Japan. Compared to other countries or regions, the selection of fast-growing types of needle-leaf forest (such as C. japonica) and the intensive forest management practiced in Japan are probably responsible for the higher ANPP of the needle-leaf forests.

All the equations of NPP and biomass in this present study were established basing on a review and analysis of field data on forest biomass and NPP (945 sets of biomass data and 572 sets of NPP data) from the five decades before 1995. All the NPP data were estimated by means of destructive sampling, so the results can be expected to be accurate.

Kira (1976) calculated NPP using the following equation:

$\Delta P_{\mathrm{n}}=\Delta Y+\Delta L+\Delta G$

where $\Delta P_{\mathrm{n}}$ is NPP, $\Delta Y$ is the net change in standing biomass per unit time (year), which represents the amount of growth, $\Delta L$ is the loss due to tree mortality, and $\Delta G$ is the biomass loss due to herbivory. Because the herbivory loss is difficult to estimate, it was not included in our sets of NPP data. Based on the results of Kira (1976) and Clark et al. (2001), the loss of biomass due to the herbivory makes the underestimation the NPP of canopy trees by about $7 \%$. Thus, the value of NPP based on the field data used in our study was slightly underestimated.

Because we used the AB-NPP relationship to estimate the forest's NPP, the quality of our allometric equations determines the precision of our ANPP estimates. Since the stand age and stand density (crown cover) varied greatly among the field data, the simulation results are not very satisfactory, even though the relationships between AB and ANPP were generally strong and statistically significant. For the other broadleaf forests and evergreen broadleaf forests, which include many species, we could not develop a single statistically significant equation for the relationship between $\mathrm{AB}$ and ANPP, but instead had to use the mean values from the field data to estimate ANPP for these forest types. Given the above limitations, it should be possible to improve the precision of our estimates by (1) collecting more field data in these forests to increase the sample size, (2) using more suitable statistical equations that account for variations in stand age and density, and (3) dividing these forests into specific subtypes based on their species composition or other factors when developing future AB-NPP equations.

In summary, we used direct field measurements and forest inventory data to establish a new database of forest biomass and NPP in Japan, and we established allometric relationships between AB and NPP for Japan's major forest types. Based on these allometric relationships and forest inventory data, we assessed the long-term changes in ANPP for Japan's forests from 1980 to 2005 . The results indicated that the mean and total ANPP of Japan's forests have increased markedly over the past $25 \mathrm{yr}$. Moreover, as was the case for Japan's carbon sink size in previous research, the ANPP of Japan's forests was higher than that of other countries or regions in the Northern Hemisphere. Afforestation based on planting of fast-growing trees and intensive forest management was the major factors responsible for Japan's higher ANPP.

\section{Supplementary material related to this article is available online at: http://www.biogeosciences.net/8/2099/2011/ bg-8-2099-2011-supplement.pdf.}

Acknowledgements. This research was supported by the National Natural Science Foundation of China (30721140306, 31021001, and 2010CB50600), the University of Tsukuba, and Peking University. The study is also partly supported by a research fund from National Institute for Environmental Studies, Japan.

Edited by: J. Yu 


\section{References}

Brown, S.: Measuring carbon in forests: current status and future challenges, Environ. Pollut., 116, 363-372, 2002.

Brown, S. and Schroeder, P. E.: Spatial patterns of aboveground production and mortality of woody biomass for eastern US forests, Ecol. Appl., 9, 968-980, 1999.

Cannell, M. G. R.: World Forest Biomass and Primary Production Data, Elsevier, New York, USA, 1982.

Chapin, F. S. III., Matson, P. A., and Mooney, H. A.: Principles of Terrestrial Ecosystem Ecology, Springer-Verlag, New York, USA, 2002.

Clark, D. A., Brown, S., Kicklighter, D. W., Chambers, J. Q., Thomlinson, J. R., and Ni, J.: Measuring net primary production in forests: concepts and field methods, Ecol. Appl., 11, 356-370, 2001.

Fang, J. Y., Liu, G. H., and Xu, S. L.: Biomass and net production of forest vegetation in China, Acta. Ecologica. Sinica., 16, 497508, (in Chinese with English abstract), 1996.

Fang, J. Y., Piao, S. L., Field, C. B., Pan, Y., Guo, Q., Zhou, L., Peng, C., and Tao, S.: Increasing net primary production in China from 1982 to 1999, Front. Ecol. Environ., 1, 293-297, 2003.

Fang, J. Y., Oikawa, T., Kato, T., Mo, W. H., and Wang, Z. H.: Biomass carbon accumulation by Japan's forests from 1947 to 1995, Global Biogeochem. Cy., 19, GB2004, 1-10, doi:10.1029/2004GB002253, 2005.

Gower, S. T., Vogel, J. G., Norman, J. M., Kucharik, C. J., Steele, S. J., and Stow, T. K.: Carbon distribution and aboveground net primary pro duction in aspen, jack pine, and black spruce stands in Saskatchewan and Manitoba, Canada, J. Geophys. Res., 102, 29029-29041, 1997.

Hertel, D., Moser, G., Culmsee, H., Erasmi, S., Horna, V., Schuldt, B., and Leuschner, Ch.: Below- and above-ground biomass and net primary production in a paleotropical natural forest $(\mathrm{Su}-$ lawesi, Indonesia) as compared to neotropical forests, Forest Ecol. Manag., 258, 1904-1912, 2009.

Hicke, J. A., Asner, G. P., Randerson, J. T., Tucker, C., Los, S., Birdsey, R. A., Jenkins, J. C., and Field, C.: Trends in North American net primary productivity derived from satellite observations, 1982-1998, Global Biogeochem. Cy., 16(2), 2, 1-15, doi:10.1029/2001GB001550, 2002.

Jenkins, J. C., Birdsey, R. A., and Pan, Y.: Biomass and NPP estimation for the mid-Atlantic region (USA) using plot-level forest inventory data, Ecol. Appl., 11, 1174-1193, 2001.

Kajimoto, T., Matsuura, Y., Sofronov, M. A., Volokitina, A. V., Mori, S., Osawa, A., and Abaimov, A. P.: Above- and belowground biomass and net primary productivity of a Larix gmelinii stand near Tura, central Siberia, Tree Physiol., 19, 815-822, 1999.
Karjalainen, T., Pussinen, A., Liski, J., Nabuurs, G. J., Eggers, T., Lapveteläinen, T., and Kaipainen, T.: Scenario analysis of the impacts of forest management and climate change on the European forest sector carbon budget, Forest Policy Econ., 5, 141155, 2003.

Kira, T.: Terrestrial Ecosystems: An Introduction, Kyoritsu Publications, Tokyo, Japan, (in Japanese), 1976.

Kira, T.: Forest ecosystems of east Asia and southeast Asia in a global perspective, Evol. Ecol. Res., 6, 185-196, 1991.

Kira, T. and Shidei, T.: Primary production and turnover of organic matter in different forest ecosystems of the Western Pacific, Jpn. J. Ecol., 17, 70-87, 1967.

Kurz, W. A. and Apps, M. J.: A 70-year retrospective analysis of carbon fluxes in the Canadian forest sector, Ecol. Appl., 9, 526547, 1999.

McNulty, S. G., Vose, J. M., and Swank, W. T.: Loblolly pine hydrology and productivity across the southern United States, Forest Ecol. Manag., 86, 241-251, 1996.

Myneni, R. B., Keeling, C. D., Tucker, C. J., Asrar, G., and Nemani, R. R.: Increased plant growth in the northern high latitudes from 1981-1991, Nature, 386, 698-702, 1997.

Myneni, R. B., Dong, J., Tucker, C. J., Kaufmann, R. K., Kauppi, P. E. , Liski, J., Zhou, L., Alexeyev, V., and Hughes, M. K.: A large carbon sink in the woody biomass of northern forests, P. Natl. Acad. Sci., 98, 14784-14789, 2001.

Nemani, R. R., Keeling, C. D., Hashimoto, H., Jolly, W. M., Piper, S. C., Tucker, C. J., Myneni, R. B., and Running, S. W.: Climatedriven increases in global terrestrial net primary production from 1982 to 1999, Science, 300, 1560-1563, 2003.

Piao, S. L., Fang, J. Y., Zhou, L. M., Zhu, B., Tan, K., and Tao, S.: Changes in vegetation net primary productivity from 1982 to 1999 in China, Global Biogeochem. Cy., 19, GB2027, doi:10.1029/2004GB002274, 2005.

Tateno, R., Hishi, T., and Takeda, H.: Above- and belowground biomass and net primary production in a cool-temperate deciduous forest in relation to topographical changes in soil nitrogen, Forest Ecol. Manag., 193, 297-306, 2004.

Turner, D. P., Koerper, D. J., Harmon, M. E., and Lee, J. J.: A carbon budget for forests of the conterminous United States, Ecol. Appl., 5, 421-436, 1999.

Whittaker, R. H. and Marks, P. L.: Methods of assessing terrestrial productivity, in: Primary Productivity of the Biosphere, Lieth, H. and Whittaker, R. H., Springer-Verlag, New York, USA, 55-118, 1975.

Xiao, C., Curielyuste, J., Janssens, I. A., Roskams, P., Nachtergale, L., Carrara, A., Sanchez, B. Y., and Ceulemans, R.: Above- and belowground biomass and net primary production in a73-yearold Scots pine forest, Tree Physiol., 23, 505-516, 2003. 